\title{
Primary nephrotic syndrome in Arab children
}

\author{
A Y ELZOUKI, F AMIN, AND O P JAISWAL \\ Department of Pediatrics, University of Garyounis, Benghazi, Libya
}

SUMmaRY We studied 134 Arab children with primary nephrotic syndrome. The annual incidence was $11 \cdot 6 / 100000$ children and the ratio of boys to girls was $1 \cdot 3: 1$. Ninety eight per cent were responsive to steroids and the mean age of the children at diagnosis was 5.7 years. On follow up (mean 29.8 months, range 1 month to 11 years) $46 \%$ had a frequently relapsing course. Renal biopsy, done in 17 patients with frequently relapsing, steroid-dependent nephrotic syndrome, showed minimal changes in 15 and mesangial proliferative lesions in two. Three of the 129 patients did not respond to steroids; two had focal and segmental sclerosis and the third had mesangial proliferative glomerulonephritis. One patient died.

In Europe, Japan, and North America most children with primary nephrotic syndrome respond to steroids and show minimal changes in renal histopathology. ${ }^{12}$ In east and west Africa nephrotic syndrome usually occurs in association with Plasmodium malariae infection, while in parts of Africa where there is no malaria, minimal change histology is rarely seen and there is poor response to steroids. ${ }^{3}$ As there are no published reports from the Arab region we have studied 134 Arab children with primary nephrotic syndrome to determine the epidemiological, clinical, and pathological features; the response to steroids; and outcome.

\section{Patients and methods}

Between 1968 and December 1982, 134 Arab children with primary nephrotic syndrome were studied at El-Fateh Children's Hospital, Benghazi. From January 1980, 86 patients were referred from other hospitals or diagnosed as new cases at our hospital. The remaining 48 patients were diagnosed at various clinics outside Benghazi before 1980 , but had been followed up at our hospital since January 1980. The children were aged between 12 weeks and 14 years. All children had heavy proteinuria $(>3.5$ $\mathrm{g} / 24 \mathrm{~h} / 1.73 \mathrm{~m}^{2}$ ) determined quantitatively, and hypoalbuminaemia (serum albumin $\leqslant 2.5 \mathrm{~g} / \mathrm{dl}$ ). None had evidence of underlying systemic disease or exposure to agents known to be associated with nephrotic syndrome.

The clinical and laboratory data were recorded and analysed as previously described. ${ }^{4}$ Percutaneous renal biopsy was done in 17 patients with frequently relapsing steroid dependent nephrotic syndrome and in three who did not respond to steroids. The methods used for the light and electron microscopy examinations and for the immunofluorescence study were standard ones.

Hypertension, uraemia, and microscopic haematuria were defined as shown in the Table. The definitions of treatment regimens, response, initial responder, initial non-responder, late responder, late non-responder, relapse, and frequent relapser have been given previously. ${ }^{5}$

\section{Results}

Incidence. The mean, annual number of new cases of primary nephrotic syndrome in children aged 14 years and below in Benghazi between 1980 and 1982 was 19; drawn from a child population aged 14 years and below of $163285 .^{6}$ This gives an annual inci-

Table Clinical and laboratory characteristics at initial diagnosis of patients who responded to steroids

\begin{tabular}{lll}
\hline Characteristics & No & $(\%)$ \\
\hline Age $>6$ years & $44 / 126$ & $(35)$ \\
Girls & $53 / 126$ & $(42)$ \\
Hypertension* (Systolic or diastolic blood & & \\
$\quad$ pressure $>95$ th centile) $\dagger$ & $12 / 77$ & $(16)$ \\
Haematuria* $>3$ red blood cells/high & & \\
$\quad$ power field) & $28 / 76$ & $(37)$ \\
Uraemia, serum creatinine, $>$ mean+2SD $\ddagger$ & $21 / 76$ & $(28)$ \\
Serum cholesterol* & $0 / 78$ & \\
$\quad<250$ mg/dl & $76 / 78$ & $(97)$ \\
$>300$ mg/dl & $3 / 44$ & $(7)$ \\
Serum $\mathrm{C}_{3}<55 \mathrm{mg} / \mathrm{dl}$ &
\end{tabular}

*Data limited to those patients diagnosed initially by us.

†As per reference 14.

¥As per reference 15 . 
dence of primary nephrotic syndrome in children aged 14 years and below of $11 \cdot 6 / 100000$. The ratio of boys to girls was approximately $1 \cdot 3: 1$ and the mean age at diagnosis was 5.7 (range $1.5-13$ ) years. Three of 111 patients $(2 \cdot 7 \%)$ had siblings with primary nephrotic syndrome. There was a positive history of allergic disorder in the patients or first degree relatives, or both, in 11 of $110(10 \%)$ children from whom a history was obtained.

Distribution of patients by response to prednisone. Two patients were lost to follow up before prednisone was started, while three patients achieved remission spontaneously. Of the 129 patients who received treatment with prednisone for 8 weeks, 126 $(98 \%)$ achieved complete remission.

Patients who responded to prednisone. The mean age of the 126 responders was 5.7 (range 1.5-13) years: $35 \%$ were older than 6 years of age and only $16 \%$ were younger than 3 years (Figure). The clinical and laboratory characteristics of the steroid responders at the time of the diagnosis are shown in the Table. Among patients who responded within 8 weeks, $38 \%$ had responded by week $1,85 \%$ by week 2 , and $96 \%$ by week 4 .

Frequent relapsers. At follow up, 58 patients (46\%) who had had complete remission from the first episode of nephrotic syndrome on prednisone treatment, followed a steroid dependent, frequently relapsing course. A trial of low dose maintenance treatment was attempted, with prednisone on alternate days. Steroid induced side effects led, however,

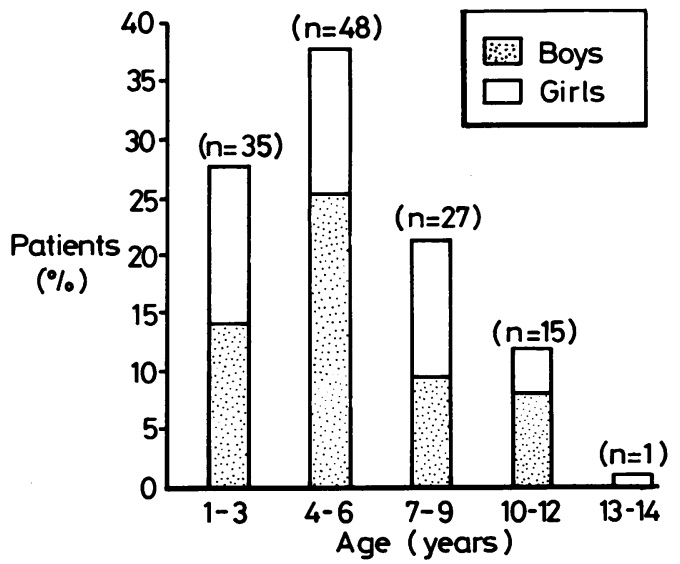

Figure Age at diagnosis and relative frequencies of boys and girls in patients with nephrotic syndrome who responded to steroid treatment. to the use of chlorambucil $(0 \cdot 2 \mathrm{mg} / \mathrm{kg} / \mathrm{day}$ in three divided doses for 8 weeks) combined with prednisone in 14 patients who are being followed up to determine the long term outcome.

Renal biopsy was performed in 17 patients with frequently relapsing, steroid dependent nephrotic syndrome from whom consent had been obtained. Fifteen patients $(88 \%)$ had minimal change lesions, whereas two patients $(12 \%)$ had mesangial proliferative lesions. In 2 of the children with minimal change lesions these were of the focal tubular change variant. ${ }^{5}$

Patients who did not respond initially to prednisone. Three of the 129 patients did not respond to the 8 weeks' treatment with prednisone (at initial diagnosis two of them had haematuria, one had hypertension, but none had azotemia). Two girls aged 6 and 7 years respectively had histological findings of focal and segmental sclerosis, and one boy aged 4 years had mesangial proliferative glomerulonephritis. These three patients went into remission 4 years, 3 months, and 9 months respectively after the initial diagnosis, while being treated with chlorambucil and prednisone combined, and have had no further relapses. All three continue to have a normal serum creatinine value.

Long term outcome. The duration of follow up averaged 29.8 months (range 1 month to 11 years) after the initial diagnosis of nephrotic syndrome. Only one patient, in whom the nephrotic syndrome was complicated by multiple thrombembolic phenomena, died. All the other children continue to have normal renal function and have not developed any evidence of systemic disease.

\section{Discussion}

Primary nephrotic syndrome was responsible for $19 \%$ of admissions to the renal unit at Benghazi. ${ }^{4}$ Our findings differ appreciably from those previously reported from Africa and from the report of the International study of kidney disease in children (ISKDC), which did not include this ethnically different group. In the present study the annualincidence of primary nephrotic syndrome was 11.6 / 100000 children, which is three times higher than that reported from Scotland or the United States. ${ }^{78}$ The ratio of boys:girls was $1 \cdot 3: 1$, while in other series $^{9}{ }^{10}$ it ranged from $2 \cdot 0: 1$ to $2 \cdot 6: 1$.

In this series $98 \%$ of children with nephrotic syndrome responded to steroids, which is higher than that reported by the ISKDC $(78 \%),{ }^{2}$ from the United Kingdom $75 \%,{ }^{1}$ and from Finland $83 \% .{ }^{11}$ In east and west Africa nephrotic syndrome often 
occurs in association with Plasmodium malariae infection $^{3}$ and there is a poor response to steroids. In a South African study of nephrotic syndrome ${ }^{12}$ only $14 \%$ of black people and $52 \%$ of those of Indian origin responded to steroids. In the present study the mean age for steroid responders was 5.7 years, only $16 \%$ were younger than 3 years and $35 \%$ were older than 6 years, while in the ISKDC study the mean age was less than 4 years and only $23 \%$ were older than 6 years of age. ${ }^{2}$ Among patients who responded initially to prednisone in the present study $38 \%$ had responded by the first week and $96 \%$ had responded by four weeks, while in the ISKDC study ${ }^{2}$ only $18 \%$ responded by the first week.

In previous reports ${ }^{19}$ the older age at onset of the disease (especially in girls), the presence of hypertension, haematuria, azotemia, and other clinical and laboratory variables were used to predict prognosis and to discriminate between certain forms of glomerular histopathology. In the present study, however, although $35 \%$ of the children were older than 6 years, $42 \%$ were girls, $37 \%$ had haematuria, and $7 \%$ had a low $\mathrm{C}_{3}$ initially, $98 \%$ responded to steroid treatment initially and all the children being followed up continued to have normal renal function. This indicates that these clinical and laboratory variables had little importance in predicting prognosis among Arab children in north Africa.

In the present study the frequent relapsers comprised $46 \%$ of the steroid responsive group and this did not differ significantly from previous studies. ${ }^{19}$

Fifteen of 17 patients (88\%) with frequently relapsing, steroid dependent nephrotic syndrome had minimal change lesions on renal biopsy, whereas two patients $(12 \%)$ had mesangial proliferative lesions and none had focal and segmental glomerulosclerosis. In a recent study from the United States ${ }^{13} 47 \%$ of 38 children with frequently relapsing steroid dependent nephrotic syndrome had minimal change lesions and $29 \%$ had focal and segmental glomerulosclerosis. In the present study where follow up varied from 1 month to 11 years (mean 29.8 months) there was one death, which was due to thromboembolic phenomena. All other patients continued to have normal renal function.

The present study provides an insight into several aspects of primary nephrotic syndrome in Arab children living in north Africa, showing the differences between this region and other parts of Africa, Europe, and those reported by the ISKDC. The reasons for the differences are not immediately apparent but possible factors, any one of which might modify a renal disorder with a presumed immunological pathogenesis, include climate and geography, types of infection to which the children are exposed, and the genetic composition of the Arab population.

We thank Professor A C Kennedy for reviewing the manuscript, Mr Badruddin Ahmed, and Ms Ingrid Rous for secretarial assistance.

\section{References}

${ }^{1}$ White RHR, Glasgow EF, Mills RJ. Clinopathological study of nephrotic syndrome in childhood. Lancet 1970;i:1353-9.

2 International study of kidney disease in children. The primary nephrotic syndrome in children. Identification of patients with minimal change nephrotic syndrome from initial response to prednisone. J Pediatr 1981;98:561-4.

3 Hendricke RG. Epidemiology and prevention of kidney disease in Africa. Symposium on renal disease in the tropics. Trans $R$ Soc Trop Med Hyg 1980;74:8-16.

${ }^{4}$ Elzouki AY, Amin F, Jaiswal OP. Prevalence and pattern of renal disease in eastern Libya. Arch Dis Child 1983;58:106-9.

5 International study of kidney disease in children. Primary nephrotic syndrome in children: clinical significance of histopathologic variants of minimal change and of diffuse mesangial hypercellularity. Kidney Int 1981;20:765-71.

6 National census: Libya, 1973.

7 Arneil GC. 164 children with nephrosis. Lancet 1961;ii:1103.

${ }^{8}$ Schlesinger ER, Sultz HA, Misher WE, Feldman JG. The nephrotic syndrome, its incidence and implications for the community. Am J Dis Child 1968;116:623.

9 International study of kidney disease in children. Nephrotic syndrome in children: prediction of histopathology from clinical and laboratory characteristics at time of diagnosis. Kidney Int 1978;13:159-65.

${ }^{10}$ Habib R. Primary nephrotic syndrome. In: Royer P, Habib R, Mathiew H, Broyer M, eds. Pediatric nephrology. Philadelphia: WB Saunders, 1974:259-60.

${ }^{11}$ Koskimies O, Vilaka J, Rapola J, Hallman N. Long-term outcome of primary nephrotic syndrome. Arch Dis Child 1982;57:544-8.

12 Adhikari M, Coovadia HM, Loening WEK. The nephrotic syndrome in children. $S$ Afr Med J 1976;50:39-43.

13 Siegel NJ, Gaudio KM, Krassner LS, McDonald BM, Anderson FP, Kashgarian $M$. Steroid-dependent nephrotic syndrome in children: histopathology and relapse after cyclophosphomide treatment. Kidney 1981;19:454-9.

14 Report of the task force on blood pressure control in children. Pediatrics 1977;59(Suppl):5,Part 2.

15 Schwartz GJ, Haycock GB, Spitzer A. Plasma creatinine and urea concentration in children: normal values for age and sex. J Pediatr 1976;88:828-30.

Correspondence to Dr A Elzouki, Department of Paediatrics, University of Garyounis, Faculty of Medicine, PO Box 1451, Benghazi, Libya.

Received 1 December 1983 